\title{
SIMBOLISMOS IDENTITARIOS AGENCIADOS EN LAS CLASES PARA 'BRASILEIRINHOS'
}

\author{
SIMBOLOS IDENTITÁRIOS AGENCIADOS NAS CLASSES DE PLH PARA \\ 'BRASILEIRINHOS'
}

\author{
IDENTITARY SYMBOLISMS AGENCIATED IN PLH CLASSES FOR \\ 'BRASILEIRINHOS'
}

\author{
Taís Cristina Samora de FIGUEIREDO ${ }^{1}$
}

RESUMEN: Este artículo es una versión modificada y reducida de uno de los capítulos de mi tesis doctoral. Presento aquí reflexiones sobre los símbolos nacionales utilizados por iniciativas, formadas por brasileñas y brasileños en el exterior, que proponen mantener y/o enseñar el Portugués como Lengua de Herencia a sus hijos y otros hijos de padre o madre brasileños, con el objetivo de despertar en los niños un "sentido de pertenencia" de también ser brasileño. Para la investigación se utilizó una metodología cualitativa que trianguló diferentes enfoques, lo que permitió mediar la comunicación entre la investigadora y sus interlocutores. A partir del trabajo etnográfico y la observación participante, presento aquí cómo los símbolos de una "brasilidad imaginada" son llevados al contexto de mantenimiento y enseñanza del PLH. Muestro cómo este universo simbólico aparece en las propuestas y prácticas pedagógicas de las iniciativas, así como las inquietudes que sustentan las metodologías y opciones didácticas para este contexto didáctico específico.

PALABRAS CLAVE: Portugués Lengua de Herencia. Inmigración brasileña. Lengua y cultura de Brasil. Cataluña.

RESUMO: Este artigo é uma versão modificada e reduzida de um dos capitulos de minha tese de doutorado. Apresento aqui reflexões acerca dos símbolos nacionais utilizados por iniciativas, formadas por brasileiras e brasileiros no exterior, que se propõem a manter e/ou ensinar o Português como Lingua de Herança para seus filhos e outras crianças com pai ou mãe brasileira, com o objetivo de despertar nas crianças um "sentimento de pertencimento" de também serem brasileiros. Para a investigação, foi utilizada uma metodologia qualitativa que triangulou diferentes aproximações, em que se permitiu mediar a comunicação entre a investigadora e seus interlocutores. A partir do trabalho etnográfico e observação participante, apresento aqui como os símbolos de uma "brasilidade imaginada" são trazidos para o contexto de manutenção e ensino de PLH. Mostro como este universo simbólico aparece nas propostas e práticas pedagógicas das iniciativas, como também as preocupações que sustentam as metodologias e escolhas didáticas para este contexto especifico de ensino.

1 Universidade Autônoma de Barcelona (UAB), Barcelona - Espanha. Doutora em Antropologia Social e Cultural, pesquisadora do Grupo de Estudos e Pesquisa "Processos Identitários e Poder" (GEPPIP) na Universidade Federal de Sergipe (UFS) - Aracaju. ORCID: https://orcid.org/0000-0002-9731-6217. E-mail: tais_samora@hotmail.com 
PALAVRAS-CHAVE: Português Língua de Herança. Imigração brasileira. Língua e cultura do Brasil. Catalunha.

ABSTRACT: This article is a modified and reduced version of one of the chapters of my doctoral thesis. I present here reflections on the national symbols used by initiatives, formed by Brazilians abroad, that propose to maintain and/or teach Portuguese as Heritage Language to their children and other children of Brazilians, with the aim of awakening in children a "sense of belonging" of also being Brazilian. For the research, a qualitative methodology was used that triangulated different approaches, which allowed mediating communication between the researcher and her interlocutors. Based on ethnographic work and participant observation, I present here how the symbols of an "imagined brazilianness" are brought to the context of maintenance and teaching of the PLH. I show how this symbolic universe appears in the pedagogical proposals and practices of the initiatives, as well as the concerns that sustain the methodologies and didactic options for this specific didactic context.

KEYWORDS: Heritage Language. Brazilian immigration. Language and culture of Brazil. Catalonia.

\section{Introducción}

Este artigo es una versión reducida y ampliamente modificada de un capítulo de mi tesis de doctorado ${ }^{2}$, en que presenta una investigación cualitativa que realicé a lo largo de cuatro años, período en el cual acompañé las acciones desarrolladas por las iniciativas de inmigrantes brasileñas en Europa de enseñanza del Portugués brasileño como Lengua de Herencia (PLH). Este es un fenómeno relativamente nuevo, que empezó a fines de los años 90, se intensificó a lo largo de los 2000 y se ha convertido en muy significativo en los diferentes países en que la inmigración brasileña está presente: primeramente, en los EE. UU., país donde se encuentra la mayor comunidad de inmigrantes brasileños, y donde se inició un proceso que se ha expandido a los países de Europa a partir de los años 2005, llegando finalmente a España y más específicamente también a Barcelona, ciudad que constituyó la unidad de observación principal de esta investigación. Para realizar la investigación fue necesaria una metodología cualitativa que trianguló diferentes aproximaciones, que permitió mediar la comunicación entre la investigadora y sus interlocutores y pensar un "enfoque etnográfico" articulando la recolección de datos documentales y datos de la observación participante.

2 Tesis defendida en noviembre de 2019 en la Universidad Autónoma de Barcelona/Es, con el título "En nombre de los "brasileirinhos"? Lengua de herencia e identidad brasileña en Cataluña", en que tuve como objetivo analizar quiénes son, por qué se organizan y cómo actúan las inmigrantes brasileñas y brasileños que constituyen asociaciones en el exterior, con la motivación de promover la llamada lengua de herencia para sus hijos, a partir de las experiencias concretas de tales asociaciones en la Cataluña.

Rev. EntreLínguas, Araraquara, v. 7, n. esp. 6, e021147, dez. 2021. 
Las personas involucradas en los proyectos de PLH en Europa, y en los otros continentes, en su mayoría son mujeres, sobre todo madres brasileñas, y proceden de varias regiones de Brasil. Aunque la mayoría de ellas sea del Sureste, hay personas del Norte al Sur del país, lo que significa que es amplia la diversidad cultural y lingüística de las madres y los padres comprometidos con la enseñanza del PLH, pues Brasil es un país con mucha diversidad cultural y lingüística ${ }^{3}$ del portugués (SAMORA, 2019). Según Dorneles (2017), las clases de POLH se imparten en un contexto de gran diversidad cultural, lo cual ha dado un sentido multicultural e intercultural a las prácticas pedagógicas, enriqueciendo aún más el universo lingüístico de los alumnos

Por ser el Brasil tan grande y tan diversificado en términos de cultura y variedad lingüísticas, precisamos también instrumentalizarlas con recursos didácticos para que esa multiplicidad cultural y lingüística enriquezca las clases de POLH (DORNELES, 2017, p. 183, traducción mía).

Aunque el objetivo principal de las iniciativas de PLH sean las clases, las prácticas pedagógicas y de encuentros que ocurren en las asociaciones son variadas, y esas prácticas son igualmente importantes para el análisis de las acciones desarrolladas, como por ejemplo: los encuentros con motivo de fechas festivas brasileñas, las reuniones y asambleas de los socios, más allá de otras actividades lúdicas que involucran canciones, juegos y teatro. Resalto que son en esos contextos cuando los elementos simbólicos regionales son activados e introducidos en la dinámica de las actividades desarrolladas.

Los símbolos nacionales, como la bandera de Brasil y los colores verde y amarillo, son frecuentemente activados como marcadores de la identidad brasileña, además del término 'brasileirinhos', usado por las agentes de PLH, que identifica la idea de una brasilidad expresada en el término. Según Jennings-Winterle y Lima-Hernandes (2015), los promotores de la cultura brasileña y representantes de las iniciativas que promueven el portugués de Brasil en los más diversos países del mundo se refieren a los niños y adolescentes que tienen conexión cultural con la lengua y la cultura de Brasil, como 'brasileirinhos', "hijos o nietos menores de edad de un o más ciudadanos brasileños que marcharon al exterior" (JENNINGSWINTERLE; LIMA-HERNANDES, 2015, p. 15). Más allá de la idea de afectividad

${ }^{3}$ Según el IPEA (Instituto de Pesquisa Económica Aplicada de Brasil), este país figura entre los de mayor diversidad lingüística. Se estima que son más de 200 lenguas, incluidas "lenguas indígenas, lenguas de inmigración, de señas, de comunidades afrobrasileñas y lenguas criollas". La lengua portuguesa es la oficial y ampliamente entendida de norte a sur del país, a pesar de las especificidades y de la gran diversidad de las acentuaciones. 
relacionada con los niños y adolescentes hijos de brasileñas o brasileños emigrados, percibo que, al tratar sobre las iniciativas que promueven la enseñanza de la lengua y cultura de Brasil para esos niños, el término 'brasileirinhos'4 se presenta como una forma de diferenciación y reconocimiento en el contexto de la migración. Algunas fundadoras de proyectos resaltan que la articulación entre las iniciativas en Europa también es una tentativa de aproximación, desde el extranjero, con el Gobierno brasileño para hacer que este "asuma su responsabilidad que concierne en la promoción, difusión y preservación de la lengua portuguesa entre las nuevas generaciones de 'brasileirinhos"'.

Destaco también que, además de las estrategias de articulación para ganar visibilidad, el movimiento de mujeres que se activan para mantener y transmitir su lengua y su idea de cultura de origen, se caracteriza por una dinámica transnacional de la inmigración, ya que buscan mantener los lazos con su tierra natal y "presentan la idea de fluidez de un lado para otro, a través de las fronteras, de personas, objetos, ideas, símbolos" (MARGOLIS, 2013, p. 242; MARGOLIS, 2008, p. 296).

El vínculo familiar (con las personas que se quedaron en Brasil) es una característica muy presente en los discursos de esas agentes, como ya destacado; la valorización de su identidad, de su idea de brasilidad en distintos contextos de migración, además de sus estrategias de reconocimiento y visibilidad en los espacios que están insertadas, hacen que esas mujeres desarrollen redes, a partir de una ideología de vida que involucra tanto a la sociedad de origen como a la de acogimiento.

Es cierto que las prácticas transnacionales han estado presentes en mayor o menor medida en los movimientos migratorios, es un hecho que las nuevas tecnologías de la información son responsables de posibilitar nuevas dinámicas y relaciones en el espacio de la inmigración, sea para investigar y obtener informaciones sobre los destinos que les interesan, sea como facilitador de contactos múltiples (estudios, empleos, viajes, vuelos baratos) o facilitando la adaptación y la reconstrucción de las vidas de los inmigrantes.

La familia que se ha quedado en Brasil, por ejemplo, no parece estar tan lejos, pues pueden hablar y mirar a sus familiares cuando lo necesiten, utilizando medios tecnológicos de comunicación, alejando la sensación de soledad. Además, en el caso específico de mi investigación, esos medios han posibilitado que personas con los mismos intereses se

${ }^{4}$ Muchas iniciativas utilizan el término para denominar sus proyectos, por ejemplo: Brasileirinhos DK; Brasileirinhos em Málaga; Brasileirinhos em Stuttgard; Casa dos Brasileirinhos em Rovigo; Clube dos Brasileirinhos, entre otros. 
encuentren y trabajen juntas, en red, buscando reconocimiento y visibilidad en los nuevos espacios de residencia, manteniendo sus vínculos con sus lugares de origen.

Las orientaciones destinadas a las profesoras y otras involucradas con el PLH están marcadas por discursos de mantenimiento de los vínculos con Brasil, en los cuales se destacan las conexiones familiares, de los símbolos y de las memorias del país. La profesora doctora Maria Luiza Ortiz, que realiza formaciones para profesores de PLH, subraya que

La lengua de herencia debe tornarse un modo de ser y de estar, un enlace que nos conduce a nuestra cultura, a nuestras raíces; aprenderla significa revitalizar nuestros contactos con ella, convivir y mantener los lazos que nos unen a ella (SOUZA; LIRA, 2017, p. 11, traducción mía).

Dorneles (2017), profesora de PLH, resalta que, en la enseñanza de POLH, la preocupación va más allá de sistematizar la enseñanza de la lengua; "es necesario considerar la enseñanza de la brasilidad como forma de crear un sentimiento de pertenencia a la lengua y cultura" (DORNELES, 2017, p. 183, traducción mía).

Destaco la definición que brinda la profesora doctora de la $\mathrm{APBC}^{5}$ acerca de la lengua de herencia:

La lengua de herencia es un idioma de comunicación relacionado con un contexto sociocultural familiar, que ayuda a estructurar el pensamiento, los discursos y sus significados. La cultura de herencia, así como también la lengua, si no es transmitida por la familia, difícilmente será aprendida, puesto que, en la mayoría de los casos, los descendientes de inmigrantes nacieron o llegaron en edad muy temprana al país de residencia (GOMES, 2017, p. 38).

Por ser la lengua de herencia una lengua transmitida por familiares y compartida con otras personas que se identifican con ella en un contexto lingüístico minoritario, los momentos de interacción en las iniciativas de PLH, especialmente los dedicados a los niños, traen para este contexto componentes que simbolizan el Brasil. Estos momentos de interacción son promovidos por padres y madres inmigrantes que consideran importantes para sus historias, su idea de persona que también pertenece, por lo menos en parte, a otro sitio y cultura. Son madres y padres en busca de hacer que sus hijos se sientan también brasileños.

5 Associação de Pais de Brasileirinhos da Catalunha/APBC, localizada en Barcelona/ES, donde realicé observación directa y participante. 


\section{Imaginario del Brasil en la enseñanza de Portugués como Lengua de Herencia}

Según Margolis (2013), la mayoría de los brasileños lleva consigo un imaginario cultural de su propia región de origen, que solo es percibido después de la llegada a cualquier lugar en el exterior. De acuerdo con la autora, la identidad nacional es una abstracción en Brasil, ya que los brasileños tienen su propio sello en el contexto de la inmigración, y muchas veces solo aprenden lo que es Brasil después que salen del país. Además de los imaginarios que esos inmigrantes llevan de sus propias regiones, hay imaginarios de Brasil más generales: como la bandera nacional, la samba, el capoeira, el día de la independencia del país, el fútbol y ciertas comidas.

Al tratar de la enseñanza de la lengua y la cultura de Brasil para niños en el extranjero, los elementos simbólicos llevados a ese contexto también son rescatados de la memoria de esas brasileñas que, a través de sus imaginarios e historias personales, buscan transmitir su lengua y su cultura.

Como he destacado anteriormente, esas brasileñas tienen su origen en varias provincias de Brasil. Se trata de un país muy extenso, con $8.516 .000 \mathrm{~km}^{2}$, caracterizado por su diversidad de clima, relieve y cultura. Cada región tiene características propias, singulares, pero, cuando hablamos de cultura brasileña fuera de Brasil, además de venir a la memoria recuerdos locales, se incorporan los símbolos nacionales.

En los eventos donde estuve sobre portugués como lengua de herencia, la orientación del trabajo pedagógico relacionado con los asuntos abordados, siempre enfatizó la idea de que cada contexto de enseñanza de PLH es singular, y es necesario, a partir de cada realidad local, programar los contenidos a ser impartidos, llevando a las clases elementos simbólicos de una idea más unificada de Brasil, además de las especificidades de origen regional de las (os) inmigrantes involucrados con sus hijos en los proyectos. Como ejemplo de estas orientaciones, durante el evento del I SEPOLH ${ }^{6}$ en Múnich, en 2015, una de las organizadoras resaltó que la lengua de herencia tiene sus especificidades, y es necesario asociar el "bagaje étnico y cultural" de los niños al contexto donde están inseridos.

Una metodología muy recurrente, que observé durante las clases en la APBC, consistía en que la profesora pedía a los niños que conversaran con sus madres o padres brasileños sobre sus vidas y sus historias de infancia, así como sobre las características de su región de origen en Brasil, y la continuación trajeran a la clase y reprodujeran estas historias para el grupo. Esto generaba una conversación entre los niños y la profesora sobre la idea de

${ }^{6}$ SEPOLH: "Simpósio Europeu sobre o Ensino de Português como Língua de Herança", evento promovido por las agentes involucradas en la enseñanza del PLH en Europa. 
diversidad regional de sus orígenes, caracterización de los modos de vida y de la simbología de lo que es imaginado como común al Brasil.

Según Gomes (2017), el punto de partida para la planificación de la enseñanza de una lengua de herencia es el vínculo afectivo y cultural que los niños tienen y, "más que conocer sus necesidades de aprendizaje, consideramos esencial desvelar las representaciones de la lengua y cultura de Brasil que los alumnos llevan consigo" (p. 275). Este argumento se ha tornado central en las defensas de los proyectos de PLH llevados adelante por las asociaciones.

\section{Gomes refuerza que}

En las clases se pueden explorar las memorias construidas por los niños a través de los viajes, de las visitas de los familiares brasileños y aun de las conversaciones constituidas en este idioma y también promover el contacto con más contextos de habla portuguesa, tales como asociaciones, eventos culturales, artísticos o demás interlocutores distintos a los familiares y profesores (GOMES, 2017, p. 277).

El PLH se ha convertido en una lengua de sentimiento que despierta todo un imaginario sobre Brasil, en este caso. Las observaciones de Gomes (2017) permiten entender la diferencia entre la metodología en la enseñanza de portugués como lengua de herencia (PLH) y el portugués como lengua extranjera (PLE). El PLH busca en el repertorio de los niños los contenidos a ser explorados, y el portugués como lengua extranjera tiene un fundamento técnico y gramatical, para aplicaciones pragmáticas. La profesora Edleise Mendes (2015) destaca que, en la mayoría de los materiales didácticos del portugués como Lengua Extranjera, o segunda lengua, por ejemplo, sobresalen los elementos del imaginario común, que representa la riqueza cultural de un pueblo, como las fiestas populares, la culinaria y las tradiciones. "La lengua, de ese modo, es vista apenas como un sistema que está al servicio de la transmisión cultural, que pasa de generación a generación, de modo uniforme y estático" (MENDES, 2015, p. 208, traducción mía).

Entiendo que, en la enseñanza del portugués como lengua extranjera, se utiliza la cultura para intentar insertar al aprendiz en un contexto, pero no activa las memorias, los sentimientos, los vínculos, como acontece en la enseñanza del portugués como lengua de herencia. La cultura abordada en LE es estandarizada, materializada, pasa a tener un significado único, como un producto.

Sin embargo, eso no significa que en la enseñanza de la lengua de herencia no están presentes los elementos de los imaginarios comunes de los involucrados; la exploración de la gastronomía brasileña; la conmemoración de fechas festivas de Brasil; la literatura brasileña, 
principalmente la infantil y juvenil; las canciones y los juegos tradicionales se conjugan con los conocimientos específicos traídos por los alumnos, además de las experiencias vividas por las brasileñas y los brasileños adultos implicados en las iniciativas. Las memorias personales de esos inmigrantes y sus sentimientos en torno a sus lugares de origen son convertidos en simbologías nacionales de la enseñanza de PLH. Por tanto, son más plurales, diversos y lúdicos, compartiendo espacio con las simbologías más homogéneas, como la bandera nacional, por ejemplo.

En las clases de la APBC, las profesoras rescataban canciones y juegos populares recurrentes en Brasil para trabajar la lengua portuguesa con los niños. Muchas veces esas canciones y juegos eran recuperados a partir de sus propias memorias de infancia. Las madres y padres también eran invitados a participar de las clases, presentando elementos culturales que formasen parte de sus regiones de origen de Brasil. En un encuentro con una madre, le pregunté como ella veía el trabajo de las profesoras considerando el origen de los socios. La madre respondió que ellas ponían mucho cuidado en atender la diversidad de orígenes en las clases, y lo ejemplificó diciendo que una vez las profesoras realizaron un proyecto para presentar todas las regiones de Brasil e invitaron a las madres y padres a ir a hablar sobre sus lugares de origen en Brasil. La madre destacó que ella les hizo un juego de memoria con frutas y animales de su región - la provincia de Pará (norte de Brasil).

Más allá de los temas regionales, pregunté a una profesora si ellas trabajaban con las fechas conmemorativas nacionales, como: la Independencia de Brasil, Día de la Bandera y el día de la Proclamación de la República, por ejemplo, que son festivas en Brasil. Ella afirmó que sí, que trabajaban las fechas de la proclamación y la independencia de Brasil solamente con los niños mayores, y el día de la bandera con todos. Esto remitía a los símbolos de una memoria nacional oficial, convirtiéndolos también en los signos que pasan a formar parte de las narrativas de la identidad brasileña en exterior, con la esperanza que tuvieran unos efectos sobre unos niños que siempre o casi toda su vida han vivido distantes del país de origen de su padre o madre, o de ambos.

Destaco que la bandera de Brasil es el símbolo nacional, utilizado por todas las iniciativas que he acompañado en la investigación, para allá de Cataluña. En los eventos, encuentros y en las sedes de las iniciativas, la bandera o sus colores constituyen la mayor representación visual de identificación con el país de origen. La referencia a Brasil es reiterada también en los logotipos de las iniciativas de las más distintas asociaciones de PLH, por los colores verde, azul y amarillo y por elementos simbólicos brasileños de la fauna, la flora, objetos culturales, juegos, niños y niñas. Subrayo que en las ilustraciones, otro símbolo 
lleno de significados son los árboles, que transmiten la idea de las raíces y conexiones entre las generaciones, un símbolo de prosperidad.

Además de la bandera brasileña y de los colores frecuentemente utilizados, las fechas de días festivos de Brasil son celebradas a lo largo del período lectivo por las iniciativas de PLH: Carnaval, Pascuas, Día de los "Indios", Fiestas de Junio, 7 de septiembre (día de la Independencia de Brasil), Día de los Niños (el 12 de octubre) y Navidad. Aunque varias fiestas no son de origen brasileño, sí tienen una forma brasileña de celebrarse. Las canciones, los juegos y la literatura de varios sitios de Brasil son utilizados y cultivados en todos los ambientes festivos, en eventos y en las clases del PLH.

La gastronomía brasileña es otro elemento explorado en la enseñanza de la cultura brasileña, con la idea de mantener la "cultura e historias vivas y presentes de nuestros "brasileirinhos" a través del cultivo de las memorias afectivas adquiridas alrededor de la mesa $^{7}$ ". La organización Brasil em Mente, en su sitio web, tiene la categoría "culinariando", en la cual incluye las recetas y la historia de algunos alimentos brasileños. Entre las comidas que más se destacan, cuando se trata de lengua de herencia brasileña, especialmente relacionado con los niños, están los platos conocidos como brigadeiro, coxinha y pão de queijo. La autora Abdala (1997 p. 161 apud MORAIS, 2011b) habla sobre el pão de queijo, comida caracterizada como Mineira ${ }^{8}$, que "permite una referencia a la tradición que se reconoce en el sabor en la infancia y en una imaginaria pureza" (p.249. Traducción mía). Yo incluyo, junto con el pão de queijo, el brigadeiro y la coxinha, que forman parte de los sabores de la infancia de muchas madres, principalmente del Sureste y Sur de Brasil.

La gastronomía de Brasil es muy variada, y cada región tiene platos específicos, que muchas veces no son muy consumidos en otras regiones del país. Según Da Matta (1986), el código de la comida es importante, pues sus posibilidades simbólicas permiten hacer una mediación "entre cabeza y vientre, entre cuerpo y alma, permitiendo operar simultáneamente con una serie de códigos culturales” (DA MATTA, 1986, p. 35, traducción mía). Según Morais (2011b), la culinaria es uno de los modos por los cuales las identidades asumen alguna materialidad, y aún puede contener discursos. "La comida también habla", dice ella (MORAIS, 2011b, p. 294). Los momentos de encuentro en las asociaciones de PLH, donde la comida forma parte del ritual, corrobora con la idea de que esta es una confraternización a la brasileña.

${ }^{7}$ Informaciones disponibles en el sitio web de la iniciativa Brasil em Mente. Disponible en: https://brasileirinhos.wordpress.com/category/culinariando/. Acceso el: 23 jun. 2019.

${ }^{8}$ Cozina mineira es referente a las comidas del Estado de Minas Gerais, localizado en el sudeste de Brasil. 
Traigo tal reflexión sobre la comida, como parte de este universo simbólico que, al lado de la literatura, de la música, de los colores, de los juegos, de los objetos culturales y de la naturaleza, ganan sentido de brasilidad. La comida "típica brasileña" traída a estos espacios de inmigración, es entendida como refuerzo para el reconocimiento y construcción de identidades, de la brasilidad que está en juego y revela un importante diálogo con la memoria de las personas.

Morais (2011a) resalta que la comida típica no es cualquier comida; su significado "representa experiencias vividas, representa el pasado y, al hacerlo, lo coloca en relación con los que viven el presente" (MORAIS, 2011a, p. 243, traducción mía), presentándose también como componentes de la memoria oficial del grupo.

Otro elemento muy explorado en la enseñanza de la lengua y la cultura de Brasil es la literatura, sobre todo la literatura infantil y juvenil. Autores clásicos de la literatura brasileña son utilizados y sugeridos como forma de realizar las actividades pedagógicas. Además de explorar escritores clásicos de la literatura infantil brasileña, como Monteiro Lobato, creador del "Sítio do Pica-Pau Amarelo" y Mauricio de Souza, creador de la "Turma da Mônica". Muy probablemente, los padres se socializaron en la infancia, a partir de esos escritores y sus personajes, a través de las escuelas brasileñas y de la difusión de estos personajes en la TV abierta.

Estos autores, personajes e historias, entre otros del género, también componían el acervo de la biblioteca de la APBC, y con mucha frecuencia las profesoras sugerían esos libros para los niños. Resalto que son historias y personajes de la infancia de los padres y madres, en un período en que en Brasil se universalizaban ciertas referencias literarias escolares y que acababan siendo lo que ellos buscaban trasmitir a los hijos como herencia brasileña en los proyectos de enseñanza de la lengua. De nuevo es la memoria de sus experiencias las que eran accionadas como vínculo simbólico y afectivo de una idea de identificación con Brasil.

Otras referencias son escritores y actores brasileños contemporáneos que hacen gira por países de Europa y también son invitados a realizar presentaciones para los 'brasileirinhos'. Los espectáculos, muchas veces, son organizados y promovidos por las iniciativas que están involucradas en la enseñanza de la lengua y la cultura de Brasil. Son presentaciones que valorizan elementos lúdicos de la forma de contar historias, de cantar y de jugar, son hablados en portugués y remiten a los universos simbólicos de las culturas regionales de Brasil. 
Las estrategias utilizadas por las iniciativas para estrechar los vínculos y acercar a los niños a Brasil, explorando elementos simbólicos brasileños a través del uso de los colores, canciones, juegos, libros y comidas, buscan a través de esos recursos dar significado en la enseñanza y aprendizaje del portugués como lengua de herencia, con la intención de hacer que los niños involucrados en estos proyectos se sientan también brasileños.

Moroni (2017), una de las principales articuladoras en Barcelona, destaca que el papel de las iniciativas es proporcionar a los aprendices de la lengua de herencia oportunidades de vivenciar prácticas culturales significativas en la lengua, ampliando el reportorio de experiencias afectivas; a partir del acompañamiento de las actividades desarrolladas por esas iniciativas en Europa. Del que he analizado, me parece que estas vienen cumpliendo los objetivos que proponen en el movimiento de la enseñanza del portugués como lengua de herencia brasileña, inclusive en el caso de Barcelona.

\section{Las experiencias pedagógicas de la "Associação de Pais de Brasileirinhos da Catalunha"}

Las actividades desarrolladas para los niños que participan de la APBC siguen un proyecto pedagógico llamado Proyecto Educativo-Cultural ${ }^{9}$. Los trabajos realizados en las clases de portugués como lengua de herencia buscan que los niños desarrollen sus competencias para interactuar en ambientes brasileños, o sea, no es solamente saber la lengua, sino también lo que se entiende por la cultura, las costumbres y los hábitos de Brasil. Según el Proyecto, al considerar la diversidad lingüística y cultural de los niños, estos son invitados a explorar y traer diferentes ejes de su identidad. Estos proyectos de enseñanza se caracterizan por la conexión entre la lengua y las referencias musicales, literarias, imágenes y juegos que tengan relaciones con el Brasil de sus madres y padres.

El Proyecto propone que las profesoras de los niños menores realicen actividades que rescaten y reinventen la cultura de la infancia: canciones de ruedas, juegos populares, narraciones de historias, muchas veces con la participación de los padres. Para los niños mayores, las actividades incluyen la lectura, la escritura y la producción de contenidos. Las celebraciones promueven encuentros que reúnen a los niños y sus familias y divulgan la cultura brasileña en la comunidad local, ya que entre los asociados predominan las familias de nacionalidad mixta, sobre todo catalán (MORONI; GOMES, 2015).

Según las profesoras de la $\mathrm{APBC}$, la dinámica pedagógica está conformada por encuentros mensuales, donde ellas hablan y piensan sobre lo que harán en el próximo período

${ }^{9}$ Más informaciones Disponible en: http://apbc.cat/. Acceso el: 29 agosto 2021. 
lectivo. Al elegir una temática, elaboran un proyecto común para todas las clases, mientras con objetivos de acuerdo con las pedagogías para los distintos grupos etarios. Después presentan a los socios (madres; padres) y entre ellos analizan lo que es viable o no y sugieren cambios y adiciones. Según una profesora con quién estuve algunas veces en campo, los proyectos nacen a partir de las necesidades de los alumnos, que son detectadas en el año lectivo corriente. A partir de las manifestaciones, narraciones y temas traídos por los niños en las clases, las profesoras conocen las memorias y expectativas de los padres, y eso permite que, posteriormente, las profesoras elaboren una pedagogía a partir de sus experiencias.

Las actividades de la asociación posibilitaban a los niños no solo el conocimiento de la lengua de Brasil, sino que también propiciaban interacciones sociales que creaban situaciones para el uso de la lengua fuera del contexto familiar. Fuera de la clase, el contacto con otros niños de diferentes edades y otros adultos que hablan portugués (que no sus padres, madres y profesores) hacía que viviesen distintas experiencias, ampliando sus vocabularios, valorizando la lengua, sintiéndose más seguros en los círculos de amistad en la asociación.

Juliana Gomes (2017), que estaba como profesora en la APBC, destaca en su Tesis sobre el tema de lengua de herencia que las clases semanales en la asociación sirven como un apoyo a las familias, pues un encuentro por semana no es suficiente para contemplar la enseñanza formal de la lengua y de la cultura brasileñas, pero es un momento de interacción social que promueve situaciones donde los niños puedan expresarse de diferentes formas en lengua portuguesa, aunque algunos se expresen más y otros menos. Para Gomes (2017), lo importante es posibilitar estos momentos de convivencia entre los niños en lengua brasileña.

La relación entre el simbolismo, el capital cultural y social, las trayectorias de las principales agentes del proceso en Cataluña y las prácticas de la asociación a través de la comprensión de qué es el PLH, remiten a los usos de un simbolismo de memorias, de cultura, de afectos y de solidaridades que sustentan este tipo de propuesta, más allá del aprendizaje de una lengua. Las socias y socios inmigrantes, sus parejas e hijos son los principales implicados por las sociabilidades producidas por los encuentros (asambleas, reuniones, talleres, fiestas) y las clases. Importa decir que las mujeres presentan un importante protagonismo en este contexto y entiendo que los "brasileirinhos" son la motivación, la lengua es el medio y la asociación el modo por el cual se concretizan sus experiencias sociales de convivio e identidades en la inmigración. 


\section{Consideraciones finales}

Este artículo tuvo como objetivo presentar como las iniciativas de PLH utilizan los símbolos nacionales y culturales de Brasil en sus trabajos de enseñanza de la lengua y cultura brasileña. Esas iniciativas están presentes en diversos países del mundo, y promueven la enseñanza del Portugués como Lengua de Herencia para 'Brasileirinhos', niños y adolescentes, hijos e hijas de inmigrantes brasileñas y brasileños. Presenté cómo los símbolos de una 'brasilidad imaginada ${ }^{10}$, son traídos al contexto de manutención y enseñanza de PLH, en especial en la Asociación de Padres de 'Brasileirinhos' en Cataluña/ES. Subrayo que la idea de "cultura brasileña" es entendida aquí como un concepto abstracto, que las y los agentes accionan y rellenan de sentido en sus trayectorias de inmigración, pero también lo hacen a partir de los sentidos más generales que se construyeran desde la academia, la literatura, las artes, los medios y la política en Brasil. Presenté cómo este universo simbólico aparece en las propuestas de eventos promovidos por las asociaciones, especialmente por la APBC, y en las prácticas pedagógicas, incluidas las clases de PLH para 'brasileirinhos', considerando la heterogeneidad (los conocimientos lingüísticos, las diferencias etarias, por ejemplo) de los niños hijos de madres y de padres de distintas regiones de Brasil.

Las prácticas pedagógicas son elaboradas a partir del rescate de un simbolismo de lo vivido, del afecto, en que las historias, los personajes, los juegos, las canciones y las comidas son recuperadas de las memorias y experiencias vividas en la infancia por las madres y los padres involucrados en los proyectos. La lengua acaba funcionando como vehículo de transmisión, además de como elemento simbólico a través del cual la dimensión afectiva se revela y es sentida en la visión de las agentes de este proceso.

Eso no significa que en la enseñanza de la lengua de herencia no están presentes los elementos de los imaginarios comunes sobre símbolos nacionales entre los involucrados, como los colores de la bandera, la conmemoración de fechas festivas de Brasil, la literatura brasileña, las canciones y los juegos tradicionales. Todo eso se conjuga con los conocimientos específicos traídos por los alumnos, además de las experiencias vividas por las brasileñas y los brasileños adultos implicados en las iniciativas. Las memorias personales de esos inmigrantes y sus sentimientos en torno a sus lugares de origen son convertidos en simbologías nacionales de la enseñanza de PLH. Por tanto, utilizan simbologías nacionales generales, que también son más plurales, diversas y lúdicas, compartiendo espacio en sus

${ }^{10}$ La idea de una "brasilidad imaginada" es inspirada en la noción de "comunidad imaginada", de Anderson (2008), donde los agentes comparten signos y símbolos comunes, que los hacen reconocerse como pertenecientes a una misma comunidad de sentimiento. 
memorias y afectos personales con las simbologías más homogéneas, como de la bandera nacional.

La relación entre el simbolismo, el capital cultural y social, las trayectorias de las principales agentes del proceso en Cataluña y las prácticas de la asociación a través de la comprensión de qué es el PLH, remiten al uso de un simbolismo de memorias, de cultura y de afectos que sustentan este tipo de propuesta, más allá del aprendizaje de una lengua. El Portugués como Lengua de Herencia está en plena expansión, asociado a los flujos migratorios que consisten en movimientos dinámicos y fluidos que dependen de los factores particulares de los lugares de destino, pero también de movimientos de las políticas gubernamentales. Estas cuestiones están intrínsecamente conectadas, pues, en la gran mayoría de los contextos, la lengua de herencia surge en la inmigración, donde es entendida como una lengua minoritaria hablada en la familia o en grupos. Como el movimiento emigratorio de brasileñas y brasileños hacia el extranjero es entendido como un movimiento todavía reciente, eso explicaría, en parte, por qué existen también esas iniciativas, pues son las inmigrantes de primera generación que salieron de su país, sobre todo en la primera década del siglo XXI para estudiar, quienes a lo largo de sus experiencias inmigratorias constituyeron familias, se convirtieron en madres $\mathrm{y}$, consecuentemente, pasaron a pensar la cuestión de la lengua relacionada con la identidad.

Resalto que estas madres, socias y fundadoras, tienen un perfil social con nivel de escolarización elevado, son consideradas de clase media, forman parejas de nacionalidades mixtas, valorizan sus orígenes y muchas de ellas amplían sus estudios, invierten en investigaciones y formaciones específicas sobre la temática. Por lo que ellas representan desde los datos cuantitativos y cualitativos en esta investigación, es posible decir que para las madres brasileñas las iniciativas también son un elemento clave favorecedor de sus posibilidades de reconocimiento, de representación política y movilidad social en la inmigración.

\section{REFERENCIAS}

DA-MATTA, R. O que faz do brasil, Brasil? Rio de Janeiro: Editora Rocco, 1986.

DORNELES, R. Material Didático para o ensino de POLH. In: SOUZA, A.; LIRA, C. (org). O POLH na Europa (Português como Língua de Herança). JNPBooks, 2017.

GOMES, J. Portugués como Lengua de Herencia en un contexto de lenguas hermanas: el caso de los hijos brasileños que viven en Barcelona. 2017. Tese (Doutorado) - Universidade 
de Barcelona (UB), Barcelona, 2017. Disponible en:

https://www.tdx.cat/handle/10803/663330. Acceso el: 10 enero 2021.

JENNINGS-WINTERLE, F.; LIMA-HERNANDES, M. C. Português como língua de Herança: A filosofia do começo, meio e fim. Nova Iorque: Brasil em Mente, 2015.

MARGOLIS, M. Goodbye, Brazil: emigrantes brasileiros no mundo. São Paulo: Contexto, 2013.

MENDES, E. A ideia de cultura e sua atualidade para o ensino-aprendizagem de le/12. Rev. Entre Línguas, Araraquara, v. 1, n. 2, p. 203-221, jul./dez. 2015.

MORAIS, L. Comida, identidade e patrimônio: articulações possíveis. História: Questões \& Debates, Curitiba, n 54, p. 227-254, 2011a. DOI: http://dx.doi.org/10.5380/his.v54i1.25749

MORAIS, P. L. Cada comida no seu tacho: ascensão das culinárias típicas regionais como produto turístico - o guia quatro rodas brasil e os casos de minas gerais e paraná (1966-2000). 2011. Tese (Doutorado) - Universidade Federal de Paraná (UFPR), Curitiba, PR, 2011b. Disponible en: https://acervodigital.ufpr.br/handle/1884/26520. Acceso el: 10 enero 2021.

MORONI, A. Português como língua de herança na Catalunha: representações sobre identificação, proficiência e afetividade. 2017. Tese (Doutorado) - Universidade Estadual de Campinas (UNICAMP). Campinas, SP. 2017. Disponible en:

http://repositorio.unicamp.br/bitstream/REPOSIP/325381/1/Moroni_AndreiaSanch ez_D.pdf. Acceso el: 10 enero 2021.

MORONI, A.; GOMES, J. O português como língua de herança hoje e o trabalho da Associação de Pais de Brasileirinhos na Catalunha. Revista de Estudos Brasileiros, Salamanca; São Paulo, v. 2, n. 2, p. 21-35, 2015. Disponible en: http://www.revistas.usp.br/reb/article/view/98538/97216. Acceso el: 10 enero 2021.

SAMORA, T. C. Em nome dos brasileirinhos: estratégias para construção identitária brasileira na Europa. Perifèria, Revista de recerca i formació en antropologia, v. 25, n. 1, p. 28-55, 2019. DOI: https://doi.org/10.5565/rev/periferia.688. 30 sept. 2020.

SOUZA, A.; LIRA, C. (org.). O POLH na Europa (Português como Língua de Herança). Birmingham: JNPBooks, 2017. 


\section{Cómo referenciar este artículo}

FIGUEIREDO, T. C. S. Simbolismos identitarios agenciados en las clases para 'brasileirinhos'. Rev. EntreLínguas, Araraquara, v. 7, n. esp. 6, e021147, dez. 2021. e-ISSN: 2447-3529. DOI: https://doi.org/10.29051/el.v7iesp.6.15437

Enviado el: 30/08/2021

Revisiones necessárias el: 17/10/2021

Aprobado el: 01/12/2021

Publicado el: 28/12/2021 